\title{
Electric Transport Properties Modified by Incomplete Cycling on Heating (ICH) in TiNi Based Alloys
}

\author{
G. Airoldi, S. Besseghini* and G. Riva** \\ Dipartimento di Fisica, Universita' di Milano, via Celoria 16, 20133 Milano, Italy \\ * ITM-CNR, Area della Ricerca di Milano, via Bassini 15, 20133 Milano, Italy \\ ** INFM, Unita di Milano Universita', via Celoria 16, 20133 Milano, Italy
}

\begin{abstract}
The investigations till now performed on the Step-wise Martensite to Austenite Reversible Transformation (SMART) have identified the relevant key features both of the transformation itself and of the Incomplete Cycling on Heating $(\mathrm{ICH})$, procedure required to induce the SMART. The SMART phenomenology, proved in several shape memory alloys, appears quite general, despite of the differences both in the kinetic and in the crystallographic characters of the thermoelastic martensitic transformations involved. The microstructural mechanism underlying SMART has however not yet been clarified. A working hypothesis, already advanced, is based on the idea that the ICH procedure is effective in inducing kinetic barriers, related to local assemblies of defects localized in the martensite phase; that, however, contrasts, at least in TiNi, with X-ray diffraction (XRD) and Electrical Resistance (ER) measurements which support an increasing structural order as a consequence of the ICH procedure. With the aim to gain further insight into the microstructural modifications in martensite, induced by the ICH procedure, ER measurements have been here undertaken both on a $\mathrm{Ti}_{49.8} \mathrm{Ni}_{50.2}(\mathrm{at} \%)$ and on $\mathrm{Ti}_{50} \mathrm{Ni}_{45} \mathrm{Cu}_{5}(\mathrm{at} \%)$ alloys. The experimental findings are discussed and contrasted with the ones already obtained on TiNi alloys.
\end{abstract}

\section{INTRODUCTION}

The striking unusual mechanical properties of the shape memory alloys rely on the thermoelastic martensitic transformation (TMT), a first-order, diffusionless transformation governed by the thermoelastic balance [1]. Once nucleated, the growth of a martensite plate depends upon both chemical and nonchemical contributions, the last being mainly related both to the elastic energy stored in the martensite, and to the frictional work required to move the transformation interface. As a consequence, the transformation kinetics is typically both athermal in character and hysteretic. However, this oversimplified picture deals well neither with the interaction among martensitic plates (self-accomodation, growth obstacles), nor with 
the boundary conditions (single or polycrystals) which are actively involved in the elastic energy relaxation processes: only in the end of 80 's the thermoelastic balance was extended to polycrystalline shape memory alloys [2]. In recent years, great efforts were made to predict the transformation path within the hysteresis cycle $[3,4,5,6,7]$, a very critical test for a theory and a crucial point in practical applications where the behaviour of a SMA actuator, as a function of temperature (and stress!), must be known.

In this frame, several investigations have been carried out on the micromemory effects induced in the TMT as a consequence of partial thermal cycles. Once defined an Incomplete Cycle on Heating (ICH) as a thermal cycle with a low temperature limit below $M_{f}$ and an high temperature limit within $A_{s}$ and $A_{f}$, where $M_{s}$ and $M_{f}, A_{s}$ and $A_{f}$ are the start (s) and finish (f) temperature of the direct or reverse martensitic transformation, it has been shown $[8,9]$ that a memory of the $\mathrm{ICH}$ high temperature limit $\left(\mathrm{T}_{\mathrm{ICH}}\right)$ is retained in the alloy provided $\mathrm{T}_{\mathrm{ICH}}$ is not exceeded, as it currently occurs during the reverse martensite $(\mathrm{M}) \rightarrow$ parent phase (P) transformation. As a matter of fact, during the following complete $M \rightarrow P$ transformation, the transformation kinetics stops at a temperature a little bit higher than $\mathrm{T}_{\mathrm{ICH}}$ (memory) and the information is wiped out: in the next complete $\mathrm{M} \rightarrow \mathrm{P}$ transformation the original kinetics is fully restored. The transformation behaviour immediately following the ICH procedure has been defined as a Step-wise Martensite to Austenite Reversible Transformation (SMART) [8]. If N ICHs are performed with a decreasing rank of the $\mathrm{T}_{\mathrm{ICH}} \mathrm{s}$, then $\mathrm{N}$ kinetic stops are found in the SMART. This kind of memory has been found in different shape memory alloys $[10,11,12]$, with different crystallographic structures and distinct hysteresis cycle widths involved, which allowed to test different levels of the non-chemical contributions involved. Assessed the key features and the generality of the SMART, the overall phenomenology was referred to as micromemory. The term memory was proposed as the transformation behaviour depends upon the history of the alloy, that is upon the ICHs. The term micro was used both to avoid confusion with the "ordinary" macroscopic mechanical memory (i.e. memory effect, pseudoelasticity); and to stress the microscopic origin of the SMART, probably strictly related to the basic properties of TMT. In order to explain the SMART, some working hypotheses have already been advanced: one based on the role of localized defects, left in the bulk after an $\mathrm{ICH}$, and acting as pinning centers of the interfacial motion; the other based on the role of a localized elastic energy relaxation, originating a lack of the driving force, during the SMART. XRD measurements performed on NiTi at $T<M_{f}$ have shown that, during a series of ICHs, the intensities of specific martensite reflections grow steadily and saturate, recovering the initial value after SMART [13]: this confirmed the reversibility of the SMART at a microstructural level, suggesting an ordering process induced by the ICHs. In order to gain further insight into the modifications induced by the ICH procedure in the martensite, electrical resistance (ER) measurements have been here undertaken both on $\mathrm{Ti}_{49.8} \mathrm{Ni}_{50.2}(\mathrm{at} \%)$ and on a $\mathrm{Ti}_{50} \mathrm{Ni}_{45} \mathrm{Cu}_{5}(\mathrm{at} \%)$ alloy. The TiNiCu alloy was chosen because the b.c.c. $\leftrightarrow$ monoclic TMT doesn't involve the R-phase [14] as in TiNi. The experimental findings are discussed and contrasted with the ones already obtained on TiNi alloys.

\section{EXPERIMENTAL}

\subsection{Materials}

$\mathrm{A} \mathrm{Ti}_{49.8} \mathrm{Ni}_{50.2}$ (at.\%) (wire, $\varnothing=1 \mathrm{~mm}$ ) and a $\mathrm{Ti}_{50} \mathrm{Ni}_{45} \mathrm{Cu}_{5}$ (at.\%) (wire $\varnothing=1 \mathrm{~mm}$ ), provided by Furukawa El.Co (J) were used. The $\mathrm{Ti}_{49.8} \mathrm{Ni}_{50.2}$ specimens were submitted to a solution treatment at $900^{\circ} \mathrm{C}(3.6 \mathrm{ks})$ under vacuum, followed by water quenching (WQ). The transformation temperatures were stabilized by $\mathrm{P} \leftrightarrow \mathrm{M}$ thermal cycling. The $\mathrm{Ti}_{50} \mathrm{Ni}_{45} \mathrm{Cu}_{5}$ specimens were aged at $450^{\circ} \mathrm{C}$ (3.6 ks) under vacuum, followed by $W Q$, in order to obtain stabilized transformation temperatures. 


\subsection{Methods}

The electric resistance measurements were performed by the conventional four $\mathrm{DC}$ terminals method (microohmmeter ESI 1701b, resolution 1 microOhm). The specimen temperature was measured by T-type thermocouples. The effect of a series of ICHs, with $\mathrm{T}_{\mathrm{ICH}} \mathrm{s}$ in a decreasing rank within $\mathrm{A}_{\mathrm{s}}$ and $A_{f}$, has been investigated.

\section{RESULTS}

\section{1 $\mathbf{T i}_{49.8} \mathbf{N i}_{50.2}$}

Fig.1 shows the ER vs. T obtained on a $\mathrm{Ti}_{49.8} \mathrm{Ni}_{50.2}$ specimen. On cooling, the specimen undergoes the well known B2 $\rightarrow R$ (rhombohedral) phase transition, followed by the $\mathrm{R} \rightarrow \mathrm{M}$ one: the transformation temperatures are $\mathrm{T}_{\mathrm{r}}=35^{\circ} \mathrm{C}, \mathrm{M}_{\mathrm{s}}=20^{\circ} \mathrm{C}, \mathrm{M}_{\mathrm{f}}=-60^{\circ} \mathrm{C}$. On heating, the $\mathrm{M} \rightarrow \mathrm{P}$ transformation temperatures are $A_{s}=12^{\circ} \mathrm{C}$ and $A_{f}=50^{\circ} \mathrm{C}$. Six ICHs were performed, with low limit temperature $-70^{\circ} \mathrm{C}$ and $\mathrm{T}_{\mathrm{ICH}}=44.5^{\circ} \mathrm{C}, 39.9^{\circ} \mathrm{C}$, $34.7^{\circ} \mathrm{C}, 29.4^{\circ} \mathrm{C}, 24.7^{\circ} \mathrm{C}, 20.2^{\circ} \mathrm{C}$ in sequence. Fig. 2 shows the $E R$, in the $M \rightarrow P$ transformation temperature range, before the $\mathrm{ICH}$ procedure (a), during (b) and after the SMART (c). The reversibility and the typical overheating are clearly evident. The variation of electric resistance respect to the value before the $\mathrm{ICH}$ procedure, at $-70^{\circ} \mathrm{C},-35^{\circ} \mathrm{C}$ and $0^{\circ} \mathrm{C}$, after each $\mathrm{ICH}$ and after the SMART are reported in fig.3(a): an overall $1.2 \%$ decrease after $6 \mathrm{ICH}$ is observed at $\mathrm{T}=-70^{\circ} \mathrm{C}$, reversibly recovered after the SMART.

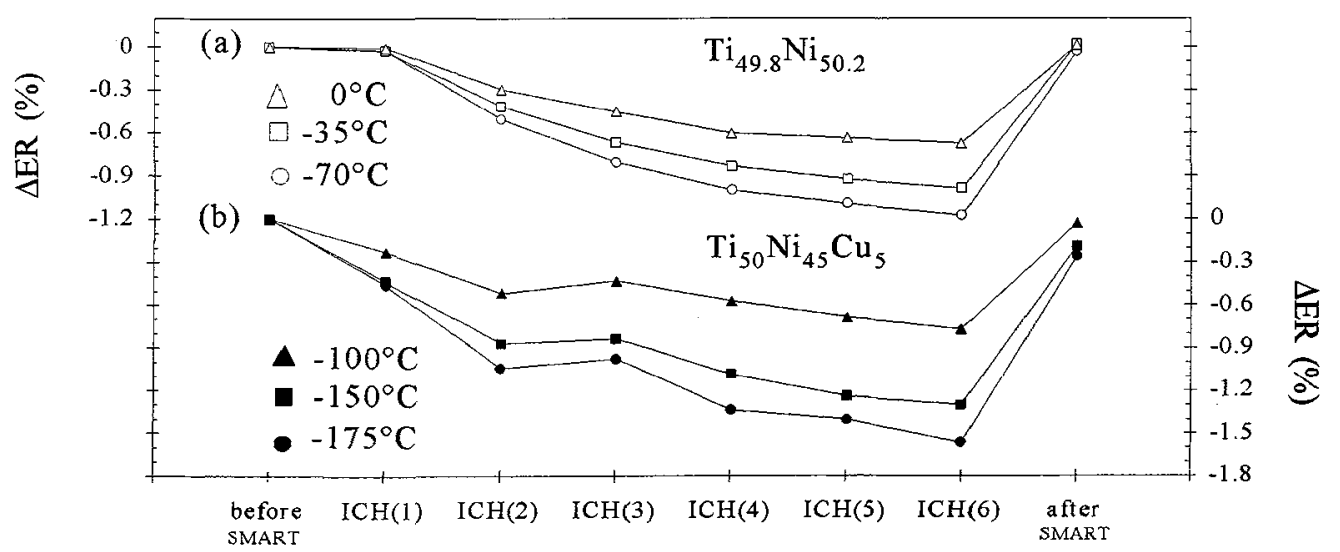

Fig.3-Variation of ER respect to the value before the ICH procedure, after each ICH and after SMART for $\mathrm{Ti}_{49.8} \mathrm{Ni}_{50.2}$ (a) and $\mathrm{Ti}_{50} \mathrm{Ni}_{45} \mathrm{Cu}_{5}$ (b) specimens. 


\section{$3.2 \mathrm{Ti}_{50} \mathrm{Ni}_{45} \mathrm{Cu}_{5}$}

Fig. 4 shows the electric resistance versus temperature obtained on a $\mathrm{Ti}_{50} \mathrm{Ni}_{45} \mathrm{Cu}_{5}$ specimen. In this case, the $\mathrm{R}$-phase is not present: only the $\mathrm{B} 2 \leftrightarrow$ monoclinic phase transition takes place, with transformation temperatures $\mathrm{M}_{\mathrm{s}}=37^{\circ} \mathrm{C}, \mathrm{M}_{\mathrm{f}}=8^{\circ} \mathrm{C}, \mathrm{A}_{\mathrm{s}}=13^{\circ} \mathrm{C}$ and $\mathrm{A}_{\mathrm{f}}=56^{\circ} \mathrm{C}$. Six ICHs were performed, with low limit temperature $-185^{\circ} \mathrm{C}$ and $\mathrm{T}_{\text {ICH }}=45.2^{\circ} \mathrm{C}, 43.2^{\circ} \mathrm{C}, 41.2^{\circ} \mathrm{C}, 39.2^{\circ} \mathrm{C}, 37.2^{\circ} \mathrm{C}$, $35.3^{\circ} \mathrm{C}$ in sequence. Fig. 5 shows the electric resistance before the $\mathrm{ICH}$ procedure, during and afterSMART in therange $\left[-185^{\circ} \mathrm{C}, 90^{\circ} \mathrm{C}\right]$.

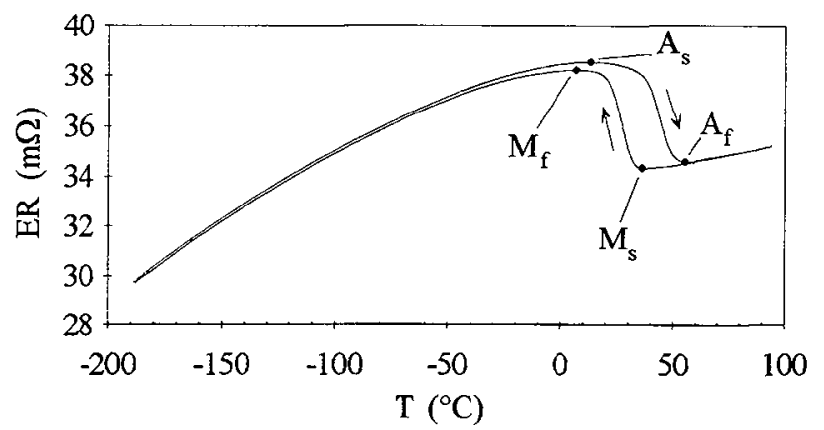

Fig.4 - ER vs. $\mathrm{T}$ for a $\mathrm{Ti}_{50} \mathrm{Ni}_{45} \mathrm{Cu}_{5}$ specimen.

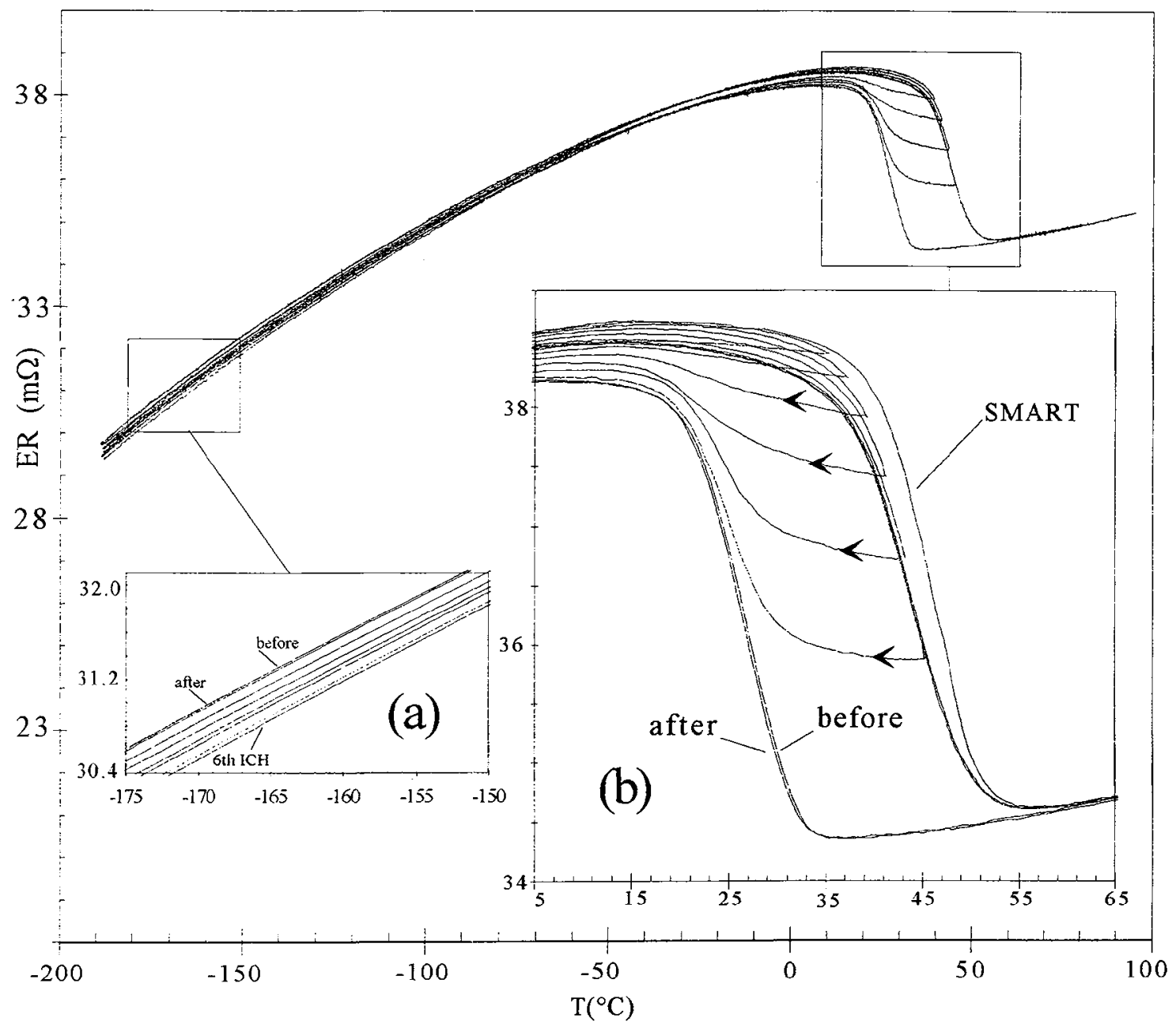

Fig.5-Modification of ER as a consequence of the $\mathrm{ICH}$ procedure in a $\mathrm{Ti}_{50} \mathrm{Ni}_{45} \mathrm{Cu}_{5}$ specimen (see text for details). 


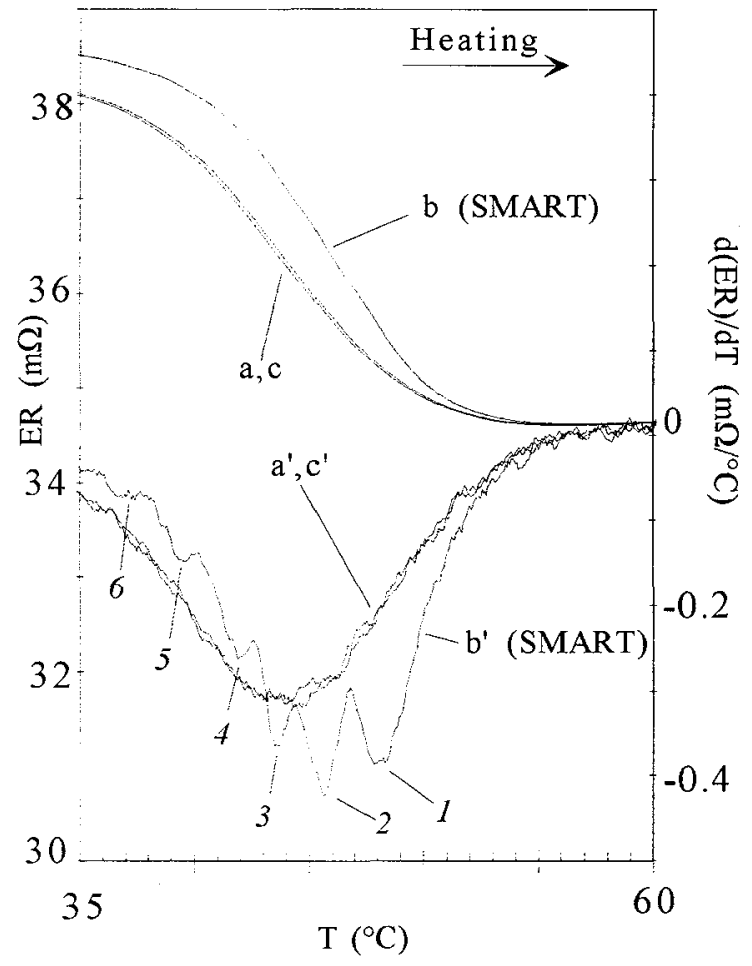

Fig.6-ER and $\mathrm{d}(\mathrm{ER}) / \mathrm{dT}$ vs. $\mathrm{T}$ before the $\mathrm{ICH}$ procedure ( $\left.a, a^{\prime}\right)$, during $\left(b, b^{\prime}\right)$ and after (c, $\left.c^{\prime}\right)$ SMART for a $\mathrm{Ti}_{50} \mathrm{Ni}_{45} \mathrm{Cu}_{5}$ specimen. The minima $I-6$ in curve $\left(b^{\prime}\right)$ are related to the 6 performed ICHs.
In the inset 5(a), the electric resistance versus temperature, on heating, in the range $\left[-175^{\circ} \mathrm{C},-150^{\circ} \mathrm{C}\right]$ is shown.

The variation of ER respect to the value before the $\mathrm{ICH}$ procedure, at $-175^{\circ} \mathrm{C},-150^{\circ} \mathrm{C}$ and $-100^{\circ} \mathrm{C}$, after each ICH and after the SMART, are shown in fig.3(b). Also in this case, at low temperature, the ER steadily decreases and saturates during the $\mathrm{ICH}$ procedure and it is restored to the original values after SMART.

In the inset $5(\mathrm{~b})$, the $\mathrm{M} \rightarrow \mathrm{P}$ transformation temperature range is depicted: the ER modifies after each ICH and recovers, after SMART, the original transformation behaviour. After each ICH, at a fixed $T$ in the $M \rightarrow P$ range, ER increases with the number of performed ICHs. This does not contrast with the results shown in the inset 5(a): it means that the martensite volume fraction, with a resistivity higher than the parent phase one, is, at that temperature, a little bit higher than in the previous ICH. Fig. 6 shows the ER and its 1st derivative in the transformation temperature range before the ICH procedure (a), during (b) and after SMART (c): curve (a) and (c) cannot be practically distinguished. The ER during SMART shows the overheating while the derivative clearly shows the presence of minima: their number is equal to the number of the performed ICHs.

\section{DISCUSSION}

The electric resistance results here obtained both on the $\mathrm{Ti}_{49.8} \mathrm{Ni}_{50.2}$ and the $\mathrm{Ti}_{50} \mathrm{Ni}_{45} \mathrm{Cu}_{5}$ alloys well agree with the XRD ones, previously obtained on another NiTi alloy [13]. In fact, both ER and XRD measurements suggest that, as a consequence of the $\mathrm{ICH}$ procedure, the degree of order in the martensite phase increases. The reversibility observed in the differential scanning calorimetry experiments (DSC) $[8,9]$, is observed also in other physical properties more strictly related to the microstructure as the electric transport properties and the XR diffraction ones. The total amount of ER decrease at a temperature $T^{*}$ in martensite, after a series of ICHs, actually depends upon $\mathrm{T}^{*}$ : the lower the $\mathrm{T}^{*}$, the higher the ER variation is. This suggests that the ICH procedure mainly affects the residual resistivity.

In order to explain the SMART, the DSC results have been interpreted [8,9] as a consequence of kinetic barriers induced by the ICHs. In fact, it is well known that, at the transformation interface, dislocation fields and stacking faults are present to accomodate the elastic strain energy involved in the lattice mismatch between parent $(\mathrm{P})$ and martensite $(\mathrm{M})$ : as the ICH induces a reversion in the direction of interfacial motion, line defects might remain in that region, acting as pinning centers, source of a localized frictional forces during the SMART. The reversibility could follow in a similar way as in CuZnAl where stacking faults have been observed disappear togheter with the martensite in the full $\mathrm{M} \rightarrow \mathrm{P}$ transformation [15]. The larger the lattice mismatch between $\mathrm{P}$ and $\mathrm{M}$ is, the higher the density of line defects and, as a consequence, a more evident SMART phenomenology (overheating, efficacy in the kinetics stop) is expected. Actually, this has been observed comparing shape memory alloys with different structural thermoelastic martensitic transformation and distinct hysteresis cycle widths involved. Under this hypothesis, however, a density of 
defects increasing with the number of ICHs is expected: this is in contrast with the ER and XRD resuits. A more sound hypothesis is based on the role of the elastic strain energy, which, in case of local relaxation, is indicated as a source of hysteresis [16]. Should the elastic strain energy somehow be locally relaxed in the zone where the reversion of the interfacial motion took place, on a thermodynamic basis, in the following $\mathrm{M} \rightarrow \mathrm{P}$ transformation, an overheating would be expected in that zone; on a microstructural basis, in martensite, an increased order could follow as a consequence of the microstress relief: hence, under this hypothesis, DSC, ER and XRD results could be univocally interpreted. The relationship between SMART and hysteresis cycle width could be then explained in this way: the more effective the elastic strain energy relaxation mechanisms are (i.e., the wider the hysteresis cycle is), the more effective the ICH procedure is.

\section{CONCLUSIONS}

The ER modifications induced by partial thermal cycles within the hysteresis cycle in a $\mathrm{Ti}_{49.8} \mathrm{Ni}_{50.2}$ (at.\%) alloy and in a $\mathrm{Ti}_{50} \mathrm{Ni}_{45} \mathrm{Cu}_{5}$ (at.\%) have been here investigated. It has been proved that the ICH procedure induces a reversible increase of the degree of order, in agreement with XRD results, previously obtained. The SMART reversibility has been proved also at microscopic level. It has been suggested that the SMART could be due to an elastic strain energy relaxation mechanism.

\section{ACKNOWLEDGMENTS}

The research has been supported by P.F. MSTA (Progetto Finalizzato Materiali Speciali per tecnologie Avanzate del CNR) of the National Research Council and by the MURST $40 \%$ funds.

\section{REFERENCES}

[1] Olson G.B. and Cohen M., Scr. Metall. 9 (1975) 1247-1254.

[2] Ortín J. and Planes A., Acta Metall. 37 (1989) 1433-1441.

[3] Wollants P., Van Humbeeck J., Aernoudt E., Delay L, Lü L., Verguts H. and Ortín J., Rev.Phys.Appl. $23(1988) 557-564$

[4] Lü L., Aernoudt E.,Wollants P.,Van Humbeeck J. and Delay L., Z.Metallkde 81 (1990) 613-622

[5] Ortín J., J.de Physique IV, Coll.C4 (1991) 65-70.

[6] Isalgué A., Amengual A., Lovey F.C., Pelegrina J.L and Torra V., Proc. Int. Conf. on Martensitic Transformations (ICOMAT-92), 20-24 july 1992, Monterey (California, USA), (Monterey Institute of Advanced Studies, 1993), pp.359-364.

[7] Seguí C., Cesari E. and Pons J., Mater.Trans.JIM 33 (1992) 650-658

[8] Airoldi G. and Riva G., "Step-wise stress-free martensitic transformation in NiTi system", in Hornbogen E., Jost N. Eds., "The Martensitic Transformation in Science and Technology", DGM Pub., Oberursel (FRG) 1989, pp.305-311.

[9] Airoldi G. and Riva G., Key Engineering Materials, 48 (1990) 5-16.

[10] Airoldi G., Besseghini S. and Riva G., "Step-wise Transformations in Shape Memory Alloys", Proc. Int. Conf. on Martensitic Transformations (ICOMAT-92), 20-24 july 1992, Monterey (California, USA), (Monterey Institute of Advanced Studies, 1993), pp.959-964.

[11] Airoldi G., Besseghini S. and Riva G., Il Nuovo Cimento, 15D (1992) 365-374.

[12] Amengual A., Scr.Met. et Metall., 26 (1992) 1795-1798.

[13] Airoldi G., Carcano G. and Riva G., J.de Physique IV, Coll.C4 (1991) 277-282.

[14] Nam T.H., Saburi T., Nakata Y. and Shimizu K, Mater.Trans.JIM 31 (1990) 1050-1056

[15] Lovey F.C., Amengual A., Torra V. and Ahlers M., Phil.Mag.A 61 (1990) 159-165.

[16] Delaey L., Ortín J. and Van Humbeeck J., "Hysteresis effects in martensitic non-ferrous all loys", Proc. Phase Transformations '87, 6-10 july 1987, Cambridge (UK), (The Institute of Metals, 1988), pp.60-66. 